\title{
The Supply Of Community Supported Agriculture
}

John M. Polimeni, (Email: polimenj@acp.edu), Albany College of Pharmacy

Raluca Iorgulescu Polimeni, Siena College

Richard L. Shirey, Siena College

Christina L. Trees, SUNY - Cobleskill

W. Scott Trees,(Email: tress@ siena.edu), Siena College

\begin{abstract}
Community Supported Agriculture (CSA) has undergone both a rapid increase in growth and interest over the last two decades. As such, the amount of literature on the subject has also increased. However, there are few, if any, theoretical models of supply for CSA memberships (shares) that have been developed from CSA farm data. This paper uses both survey and anecdotal data from the Roxbury Biodynamic Farm, one of the largest CSA in the United States, to present a theory of supply for CSA membership. Included in the discussion is the consideration that CSA farms are not profit maximizing and that the farmers (i.e. the suppliers) knowingly take on the responsibilities and earnings associated with a CSA.
\end{abstract}

\section{INTRODUCTION}

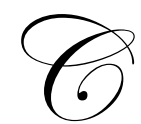

ommunity Supported Agriculture (CSA) originated in Japan in the early 1970's and came to the United States in 1985, and has experienced rapid growth and evolution since then. During this twenty year time period, the CSA movement has grown to well over 1,000 farms. This has led to a concurrent increase in the number of articles and books on the subject by, among others, economists, sociologists, and anthropologists on topics such as how to successfully run and organize a CSA farm (VanEn 1992; DeLind 1990), analyzing the aspects of participation in community building (Cone and Myhre 2000), the pricing of CSA shares (Cooley and Lass 1997, 1998), and technology used in CSA production (Lass and Sanneh 1996). However, little has been written about the nature and complexity of supply for CSA membership, which, for the purposes of this paper, is assumed to be equivalent to the supply of organic produce. There is a strong relationship among CSA members, farmers, and agricultural production, and this dynamic cannot be captured by models that focus on the power of consumer sovereignty. This is not surprising since non-price factors influencing supply are rarely used in traditional microeconomic analysis

A typical microeconomic supply model of agricultural produce focuses on prices. The supply of agricultural produce has long been considered a function of prices, extending back to Nerlove (1958) who estimated the supply elasticity for corn, cotton and wheat in the United States. Agricultural supply models were furthered developed in the 1970's (Askari and Cummings 1977), the 1980's (Binswanger 1989), and to today (Lamb 2000). Nonetheless, these models do not capture the uniqueness that has led to the tremendous growth of CSA.

Some of the growth can be attributed to increased demand for organic produce. However, much of this growth of CSA is due to farmers finding innovative methods of sustaining their economic feasibility to counteract rising land prices and low prices for agricultural products. Thus, CSA farmers have focused on product diversification, growing organic produce, introducing new agricultural products, and using innovative marketing techniques (Lass, Lovoie, and Fetter 2005). Using these methods, farmers are able to capture the premium prices that they can receive for their organic produce. However, despite this ability to attract premium prices, many CSA farms are not sustainable economically. 
Several factors contribute to the economic instability of CSA farms. Because production methods are mostly organic, and the health and sustainability of farmland are recognized goals, CSA farms are more susceptible to factors beyond their control, such as hail, frost, drought, pests and weeds, than traditional farms. However, unlike traditional farms, if the quality and/or the quantity of CSA products are affected, the farmer's short-run income or short-run profit is unaffected because members share the risk with the farmer. However, if the quantity and/or quality of the produce are severely affected, then some members will choose to opt out of their relationship with CSA after the growing season, negatively affecting the profit of the farm and the income of the farmer in future years, and increasing the likelihood that a farm will cease operations.

Therefore, a key component of the economic viability of a CSA is linked to the social interaction, or personal bond, with the farmer. The farmer provides information to the members, informing them of day-to-day operations, as well as practical and useful information on how to prepare and store the produce. Furthermore, this relationship provides information to the farmer as well. Members let the farmer know which vegetables they like and do not like and which vegetables they receive too much of and too little of. With this information, the farmer decides how to allocate his or her resources.

Classical studies are supply-side dominated, and resource allocation by suppliers is largely determined by consumer decisions about which goods and services to purchase. This relationship was first coined by Hutt (1936) as consumer sovereignty. A sovereign consumer transfers resources from less to more socially valued uses. Individual interests should be strongly discouraged, if not bought out, and freedom of the individual is guaranteed when market operations are performed with impersonality and impartiality (Reekie 1988). Norton et al. (1998) highlight the stress between social and individual interests when examining consumer sovereignty and environmental sustainability. They find that a command-and-control approach makes people feel deprived of contributing to sustainability, whereas an approach that allows preferences to influence decision-making makes people better-off and proud to contribute to sustainability. Consumers, with altruistic motives, are capable and often willing to make consumption choices which do not improve and may decrease their welfare (Paavola 2001). But if we move beyond welfare being defined as traditional Pareto optimality, and we acknowledge that interpersonal utility functions not only exist, but are critically important to CSA, then interactions with the farm, farmer, and other members can be viewed as necessary for sustaining and deepening consumer demand for CSA. In essence, tastes and preferences change as the social institution (the farm) changes.

This paper seeks to develop a theoretical approach of supply for CSA membership that incorporates the uncertainties and social institution changes described above. The development of a model of supply that is socially diverse and ecologically regenerative is an important achievement for both the CSA community and the rest of agriculture in the United States (Lass, et al. 2003). To accomplish this task, anecdotal and survey data from Roxbury Farm, a CSA farm in rural Columbia County, New York, will be used. The Roxbury Farm CSA was started in 1990, and his since become one of the largest CSA farms in the United States, with more than 950 members or an estimated 2,000 or more consumers. Members of the Roxbury Farm come from three distinct regions: (1) a third from New York City, (2) a sixth from Columbia County, and (3) half from the Capital District area near Albany, New York. From early June through December, produce is delivered to different distribution sites where members go to pick up their share, usually during a two to four hour period on a designated day. Typically, members receive 400 pounds of vegetables per year, all of which are grown on just thirty of the over one hundred forty acres of land on the farm.

The organization of the remainder of the paper is as follows. In section 2, a description of CSA farming is provided. Section 3 presents a model of supply for CSA using traditional microeconomic analysis. Section 4 offers an alternative model of supply for a CSA. Section 5 concludes the paper with discussions and implications of the analysis provided.

\section{WHAT IS CSA?}

Community Supported Agriculture, broadly defined, is a group of people who share in both the production and consumption of agricultural output. To those unfamiliar with the concept, CSA farms might seem to share a number of more specific characteristics than this definition implies. This would be misleading, however, as CSA 
farms are really quite diverse. For example, CSA can produce year round in some regions of the country, but the growing is limited and varies in other regions. Larger ventures may have full-time farmers who use available technology, while smaller farms may have a part-time farmer or no farmer at all, and little access to technology. Most CSA farms are organic, diverse in the variety of production, and focused on fruits and/or vegetables. However, there are notable exceptions. Some CSA farms provide meat and dairy products to their members for an additional fee. Thus, CSA can have a different meaning depending upon location, scale, and both the method and nature of production.

In this context, even the concept of community does not necessarily mean a geographic location, and sharing in production does not mean that members always provide labor. In short, CSA is a community where members share common goals and share many of the same experiences in trying to achieve these goals. Members provide financing to the farm by buying shares, typically much in advance of the growing season, which entitles them to a part of the food that is grown. Furthermore, members are expected to contribute a few working hours on the farm or distribution site or pay a small premium to opt out of this requirement. This method of financing is important because members share the risk and uncertainty inherent in agricultural production (Lamb 1996; Padel and Lampkin 1994), allowing the farmer to purchase the seeds and other production goods and to have a guaranteed income for the year (Stern 1992; Karr 1993). Just as important, it allows the farmer to avoid the cost of holding short-term debt.

\section{A TRADITIONAL THEORY OF CSA SUPPLY}

The supply for CSA shares is not simply a supply for vegetables, for if it were, competition from food cooperatives, farmers markets, and local supermarkets would likely eliminate CSA farms. Furthermore, for that period of time during each year when vegetables cannot be grown, CSA members must purchase their produce from one of the other sources of competition, necessitates recidivism on the part of the CSA, if the CSA is to continue operations.

Therefore, a new approach for a theory of CSA supply must be developed. However, for comparability purposes, a traditional microeconomic approach to CSA membership supply will be examined first. Equation 3.1 provides an example of how the quantity of CSA memberships produced is typically modeled.

$Q_{v}=f\left(P, P_{k}, P_{w}, P_{L}, P_{M}, I, T, J, O, E_{s}\right)$

Where $Q_{v}=$ the quantity of CSA farm memberships produced, represented as the supply

of bundles of vegetables

$P=$ the price of a CSA farm membership, treated as the price of a bundle of vegetables

$P_{k}=$ the rental rate of capital

$P_{w}=$ the wage rate for farm labor, administrators, apprentices, and interns

$P_{L}=$ the lease rate of farm land

$P_{M}=$ the cost of marketing and retailing

$I=$ interest rates, both short and long-term

$T=$ taxes

$J=$ technology

$O=$ the opportunity cost to the farmer

$E_{s}=$ expectations (including expected inflation, $P_{e}$ )

The variables $P, P_{k}, P_{w}, P_{L}, P_{M}$, and $I$ in equation 3.1 are straight-forward and self-explanatory. Other variables, however, may not be so self-evident. $T$ is included in the supply function because taxes for CSA farms varies by location, and some farms are designated as not-for-profit. For the case study presented in this paper, 
Roxbury Farm is a limited liability, for profit corporation. $J$ is rarely included in traditional models as an explicit variable. Rather, technology is often captured in the algorithm that details the relationship between labor and capital in the production function. $J$ is explicitly defined in this paper because the demand for organic vegetables is intertwined with the specific technology used on the farm. In other words, CSA members are interested in the method used to produce the vegetables. The farmer can use advances in technology to reduce the costs of production through economies of scale, but often these methods are not organic, and, thus, counter to member preferences. $O$ to the farmer is both the value of the land, which could be sold for development, and of growing organic vegetables. Similar to the technology variable, farmers could increase the production of vegetables, and rate of return, by growing nonorganic produce. $E_{s}$ represents the expectations of the farmer. If the expectations of the farmer for the number of memberships are low, then the supply of organic vegetables will be small. However, if the expectations of the farmer are high, then supply of organic vegetables will be large. At the same time, supply, or $Q_{v}$, will also be impacted by the expected rate of inflation during the growing season.

\section{AN ALTERNATIVE THEORY OF CSA SUPPLY}

Unfortunately, the model represented by equation 3.1 obfuscates more than it reveals. The quantity supplied of CSA memberships, even when reduced to the supply of organic vegetables, is not determined by price. For a CSA farm, the first step is to determine the number of shares that will be supplied. Although demand for membership does impact this decision, so, too, does the supply of available resources. In essence, the number of shares is limited by the available physical resources, including usable land, which is fixed for any given growing season, capital, and technology. Once the decision is made as to the number of memberships to be offered each year, the cost of each membership is then estimated. In order to determine the price $\left(P_{t}\right)$ in equation 4.1, a profit target is set which establishes the minimum income necessary to compensate the farmer. The cost of each share is then increased by the profit target divided by the number of memberships. This means that price is, in part, a function of the supply of memberships, not the reverse. It also means that profit maximization is not a guiding principle.

$P_{t}=g\left(\pi_{t}, Q_{S t}, P_{K t}, P_{W t}, P_{L t}, I_{t}, T, E_{S t}\right)$

Where $P_{t}=$ the price of a CSA farm membership in year $\mathrm{t}$

$\pi_{t}=$ the profit target of the CSA in year $\mathrm{t}$

$Q_{S t}=$ the quantity of CSA memberships supplied in year $\mathrm{t}$

$P_{K t}=$ the rental rate of capital in year $\mathrm{t}$

$P_{W t}=$ the wage rate for farm labor, administrators, apprentices, and interns

$P_{L t}=$ the lease rate of farm land in year $\mathrm{t}$

$I_{t}=$ long-term interest rates in year $\mathrm{t}$

$T=$ taxes in year $\mathrm{t}$

$E_{S t}=$ expectations in year $\mathrm{t}$

While capital and technology may not be fixed, they are often predetermined by nature and the chosen production method, which in this case means organic and bio-diverse. The decision to be organic itself is influenced indirectly by members demand for organic produce. Thus, capital and technology are not chosen to maximize output irrespective of other goals. This relationship is illustrated in equation 4.2. 


$$
\begin{aligned}
& Q_{S t}=g\left(\bar{H}, K_{t}, J_{t}, E_{S t}\right) \\
& \text { Where } \bar{H}=\text { a fixed number of acres or hectares of farmland } \\
& K_{t}=\text { capital in year } \mathrm{t} \\
& J_{t}=\text { technology in year } \mathrm{t} \\
& E_{S t}=\text { expectations in year } \mathrm{t}
\end{aligned}
$$

If, as the season progresses, unforeseen costs arise, members are not expected to pay more for their shares. Instead, the farmer will receive less income than the profit target. However, if factors beyond the control of the farmer, such as bad weather, affect the quantity and/or quality of vegetables, then the farmer's income will not be affected in year $t$. Rather, the farmer will likely be affected in year $t+1$. If the members, who share risk with the farmer in the short-run, decide that they are dissatisfied with the crop yield or quality, then the members will not renew their membership to the farm, creating losses for the farmer in the long-run. Thus, $I_{t}$ in equation 4.1 measures long-term interest rates, as opposed to $I$ in equation 3.1,.which measures both long and short-term interest rates. It should be added that negative scenarios are not the only potential deviation from expectations. For instance, the harvest might be unusually bountiful, in which case the farmer receives the profit target and members receive a quantity and/or quality of vegetables that exceed expectations.

An obvious result of the above discussion is that $\pi_{t}$ is different than profit maximization for a CSA.

However, $\pi_{t}$ is consistent with the motivation that drives farmers to take on CSA responsibilities. In contrast to large-scale conventional farms, whose end-product is often money, the end-product or a CSA is the health of the farm, the farmer, and the farmer's community (McCabe 1998). Furthermore, the motivation of many CSA farmers and members is to heal the planet, while providing education to the community and implementing socially just, and ecologically sound agriculture (Wann 2001). These end-products and motivations are, in some sense, a necessity because many CSA members are attracted to the idea that they are supporting farmers who embrace these very goals (Polimeni et al. 2005). Moreover, if the CSA is a core group farm, that is a farm where members provide labor, then the farmer will not have to employ as many workers and can use alternative land-use agreements that positively affect the income of the farmer (Lass et al. 2003).

It is worth highlighting that Roxbury Farm has a very active internship program which is a fundamental part of its educational mission. Interns live and work on the farm while learning the techniques of running a successful CSA. In return, Roxbury Farm has access to a dedicated and skilled labor force which costs less than would otherwise be the case. Interestingly, several former apprentices have gone on to start their own CSA farms, and some of these are in relatively close geographic proximity to Roxbury Farm. While traditional thinking might perceive this as a threat, Roxbury Farm members view it as an important benefit to the community, and there is certainly no evidence that it has hurt Roxbury Farm membership, which routinely has a waiting list for shares.

\section{DISCUSSION AND IMPLICATIONS}

Although the goals of many CSA farmers are different from their traditional farming counterparts, the dayto-day skills and knowledge needed to grow agricultural produce is very similar. However, one major difference between a CSA farm and a traditional farm is the amount of money and time spent on marketing and retailing. A traditional farm spends countless hours and money on marketing and advertising. Furthermore, a CSA does not have this problem because the majority of members learned about the CSA through word-of-mouth, not formal advertising. Typically, a CSA will spend $80 \%$ of their time farming and $20 \%$ marketing (Wann 2001).

The characteristics described previously have not traditionally been important in agriculture. However, for a CSA these characteristics are vital to being successful, reflecting the notion that CSA memberships are about more than fresh, organic, locally grown produce. The role of the farmer and his/her choice of production methods should be emphasized in the demand for memberships (Polimeni et al. 2005). 
Few, if any, models of supply for CSA have been developed and disseminated, largely due to the complexity inherent in the relationships among the land, the farmer, the members, and the vegetables. However, despite this lack of research, the supply of CSA is becoming increasingly important as CSA's grow in popularity. This paper offers a theoretical model of supply based on experiences at one of the largest CSA in the United States, Roxbury Farm. Nevertheless, the model presented in this paper extends to most other successful CSA farms.

\section{REFERENCES}

1. Askari, H. and J.T. Cummings. 1977. Estimating Agricultural Supply Response With the Nerlove Model: A Survey. International Economic Review 18: 257 - 292.

2. Binswanger, H., 1989. The Policy Response of Agriculture. Proceedings of the World Bank Annual Conference on Development Economics 1989 Washington, D.C.

3. Cone, C.A. and A. Myhre. 2000. Community-Supported Agriculture: A Sustainable Alternative to Industrial Agriculture. Human Organization 59: 187 - 202.

4. Cooley, J. and D. Lass. 1997. What's Your Share Worth? Some Comparisons of CSA Share Cost Versus Retail Produce Value. 1997 CSA Farm Network, Northeast Organic Farming Association.

5. $\quad$---------- 1998. Consumer Benefits from Community Supported Agriculture Membership. Review of Agricultural Economics 20: 227 - 237.

6. DeLind, L.B. 1990. Close Encounters With a CSA: The Reflections of a Bruised and Somewhat Wiser Anthropologist. Agriculture and Human Values 16: 3 - 9.

7. Hutt, W.H. 1936. Economists and the Public. London: Jonathan Cape.

8. Karr, P. 1993. The Last Best Hope for Family Farms. Sanctuary, Journal of the Massachusetts Audubon Society 32: $5-9$.

9. Lamb, G. 1996. Community Supported Agriculture: Can It Become the Basis for a New Associative Economy? In: S. Gilman (ed.) 1996 CSA Farm Network. Stillwater, NY: Northeast Organic Farming Association.

10. Lamb, R. 2000. Food Crops, Exports, and the Short-run Policy Response of Agriculture in Africa. Agricultural Economics 22: 271 - 298.

11. Lass, D.A., G.W. Stevenson, J. Hendrickson, and K. Ruhf. 2003. CSA Across the Nation: Findings from the 1999 CSA Survey. Center for Integrated Agricultural Systems October.

12. Lass, D.A., N. Lavoie, and T.R. Fetter. 2005. Market Power in Direct Marketing of Fresh Produce: Community Supported Agriculture Farms. University of Massachusetts Amherst Department of Resource Economics Working Paper No. 2005-2.

13. Lass, D.A. and N. Sanneh. 1996. Costs and Returns for CSA Operations in the Northeast: Preliminary Results from the 1996 Survey. http://www.umass.edu/resec/fac+staff/csa1.html

14. McCabe, M. 1998. Farming in the 90's: Cultivating Community Roots. San Francisco Chronicle September 11.

15. Nerlove, M. 1958. The Dynamics of Supply: Estimation of Farmer's Response to Price. Baltimore: Johns Hopkins University Press.

16. Norton, B., R. Costanza, and R. Bishop. 1998. The Evolution of Preferences: Why Sovereign Preferences May Not Lead to Sustainable Policies and What to do About It. Ecological Economics 24: $193-211$.

17. Paavola, J. 2001. Towards Sustainable Consumption: Economics and Ethical Concerns for the Environment in Consumer Choices. Review of Social Economy LIX: 227 - 248.

18. Padel, S. and N.H. Lampkin. 1994. Farm-level Performance of Organic Farming Systems: An Overview. In: N.H. Lampkin and S. Padel (eds.) The Economics of Organic Farming: An International Perspective. Wallingford: CAB International.

19. Polimeni, J.M., R. Iorgulescu Polimeni, R.L. Shirey, C.L. Trees, and W.S. Trees. 2005. The Demand for Community Supported Agriculture. Journal of Business and Economics Research. Forthcoming.

20. Reekie, W.D. Consumers Sovereignty Revisited. Managerial and Decision Economics 9: 460 - 470.

21. Stern, P. 1992. Subscription Squash, and Celery, and Spinach, etc. In Context: A Quarterly of Humane Sustainable Culture 31: 8.

22. Wann, D. 2001. Organic Farmers Forge Links with Consumers. Denver Post November 25. 